\title{
WestVirginiaUniversity
}

THE RESEARCH REPOSITORY @ WVU

Graduate Theses, Dissertations, and Problem Reports

2021

\section{Productivity Index for Unconventional Gas Wells}

Yousef Khajah

yfkhajah@mix.wvu.edu

Follow this and additional works at: https://researchrepository.wvu.edu/etd

Part of the Other Engineering Commons

\section{Recommended Citation}

Khajah, Yousef, "Productivity Index for Unconventional Gas Wells" (2021). Graduate Theses, Dissertations, and Problem Reports. 7997.

https://researchrepository.wvu.edu/etd/7997

This Problem/Project Report is protected by copyright and/or related rights. It has been brought to you by the The Research Repository @WVU with permission from the rights-holder(s). You are free to use this Problem/Project Report in any way that is permitted by the copyright and related rights legislation that applies to your use. For other uses you must obtain permission from the rights-holder(s) directly, unless additional rights are indicated by a Creative Commons license in the record and/ or on the work itself. This Problem/Project Report has been accepted for inclusion in WVU Graduate Theses, Dissertations, and Problem Reports collection by an authorized administrator of The Research Repository @ WVU. For more information, please contact researchrepository@mail.wvu.edu. 
Graduate Theses, Dissertations, and Problem Reports

2021

Productivity Index for Unconventional Gas Wells

Yousef Khajah

Follow this and additional works at: https://researchrepository.wvu.edu/etd

Part of the Other Engineering Commons 
Productivity Index for Unconventional Gas Wells

Yousef F. Khajah

Report Submitted to

Benjamin M. Statler College of Engineering and Mineral Resources at West Virginia University

In Partial fulfillment of requirements for the degree of

Master of Science

In

Petroleum and Natural Gas Engineering

Kashy Aminian, Ph.D., Chair

Samuel Ameri, Ph.D.

Ilkin H. Bilgesu, Ph.D.

Department of Petroleum and Natural Gas Engineering

Morgantown, West Virginia

2021

Keywords: Productivity Index, Unconventional Reservoirs, Horizontal Well, Hydraulic Fracturing

Copyright 2021 Yousef F. Khajah 


\author{
Abstract \\ Productivity Index for Unconventional Gas \\ Wells Yousef F. Khajah
}

Productivity Index reflects the ability of a well to produce hydrocarbons and is often used to analyze the well's performance. Productivity Index is the ratio of the flow rate to the drawdown pressure under pseudo-steady state flow conditions. The unconventional gas formation such as shale are the main target of the gas exploration and production. The application of horizontal drilling and hydraulic fracturing technologies have been instrumental in development of shale gas resources. The evaluation of the productivity index for unconventional gas wells is however challenging because the production mainly occurs under the transient conditions.

This research aims to evaluate the transient productivity index for a horizontal well with multiple hydraulic transverse fractures drilled in an ultra-low permeability gas formation. Additionally, the impacts of different hydraulic fractures configurations are investigated. The approach taken to conduct this research study was to build a reservoir model using CMG simulation software, identify the production periods for different flow regimes, estimate the average productivity index for the infinite-acting period, and finally perform a sensitivity analysis and compare different well configurations.

The results of the study indicate that the fracture half-length and to a lesser extent the fracture spacing impact both the duration of transient flow and the productivity index of the horizontal well. The fracture conductivity was however found to only have minor impacts on transient flow duration and the productivity index. 


\section{ACKNOWLEDGMENT}

I would like to thank my research advisor Dr. Kashy Aminian for supporting me and giving me this invaluable experience. I would like to thank and acknowledge Mohamed El Sgher

for his help and guidance. I would like to thank Dr. Ilkin Bilgesu for his kind help and support.

I would like to thank Dr.Samuel Ameri for his continuous support, encouragement, and for all the opportunities I was given.

I would like to express my gratitude to my parents and family. Without their support, it would be impossible for me to complete my study. 


\section{Table of contents}

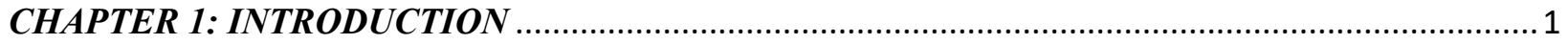

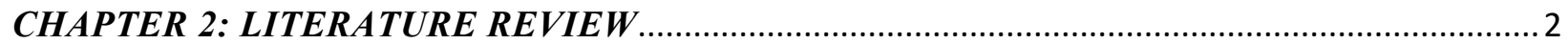

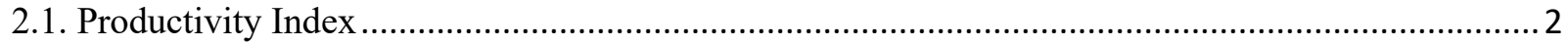

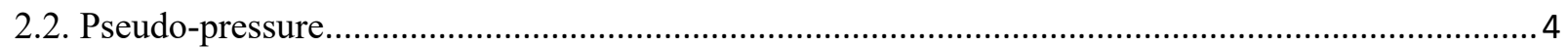

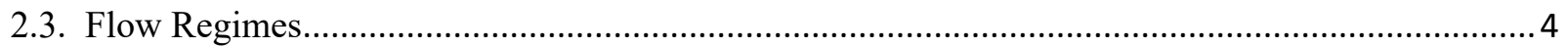

(1)

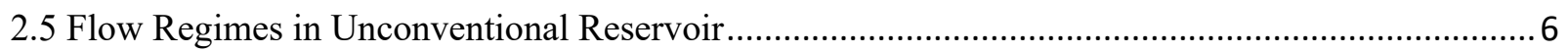

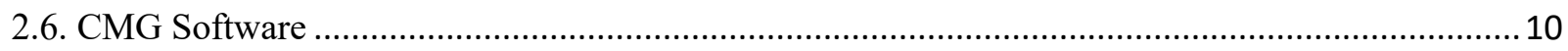

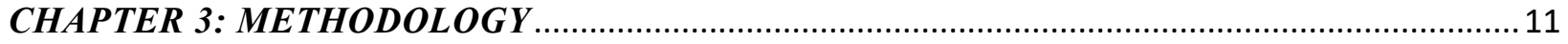

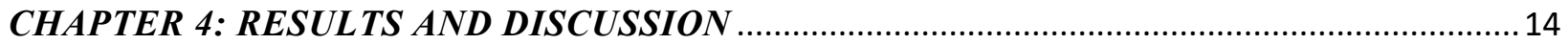

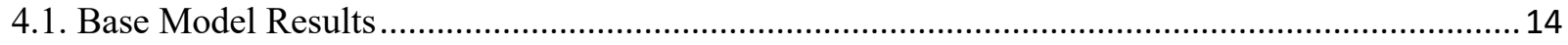

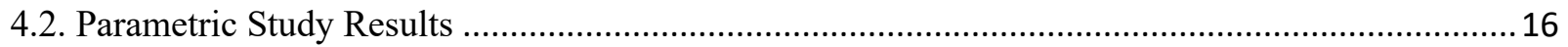

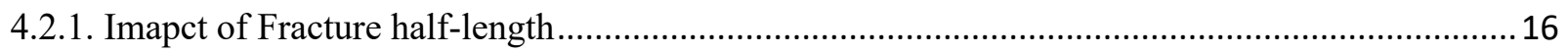

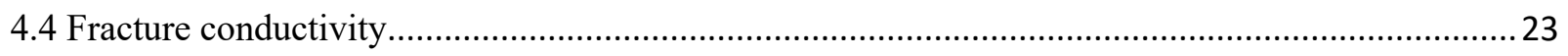

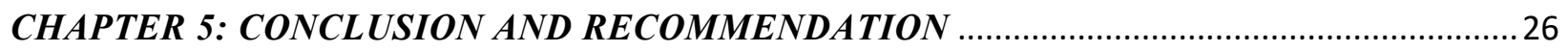

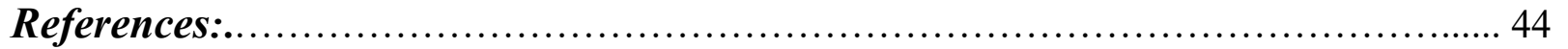




\section{List of Figures}

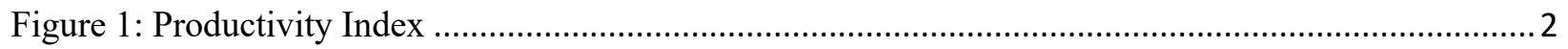

Figure 2: Pressure Disturbance ..................................................................................................... 5

Figure 3: Psuedo-Pressure Derivative Responses for a Horizontal well in a Homogenous Reservoir (After

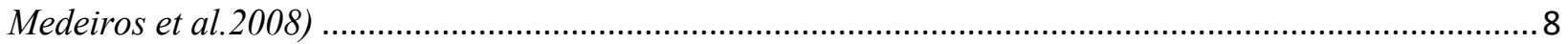

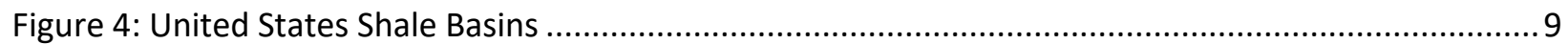

Figure 5 : Marcellus and Utica Shale Formation Map .................................................................. 10

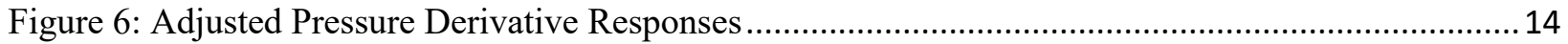

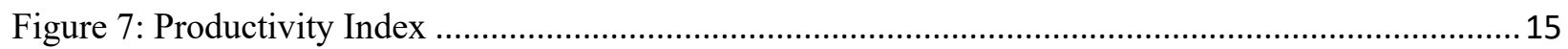

Figure 8: Derivative Responses for different fracture half-lengths .................................................. 16

Figure 9: Productivity Index Plot for Different Fracture half-Length .................................................. 17

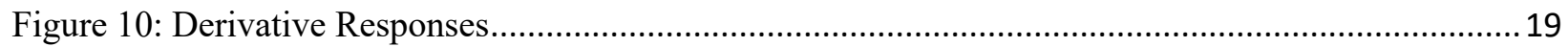

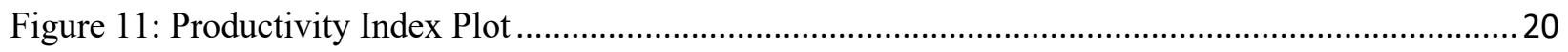

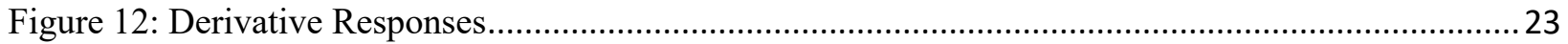

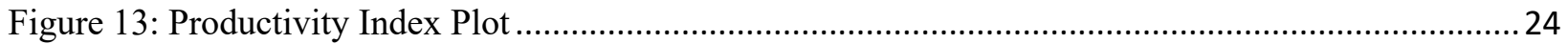




\section{List of Tables}

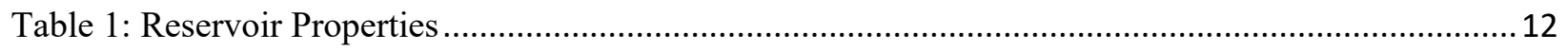

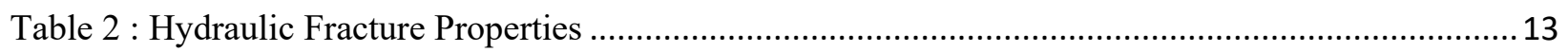

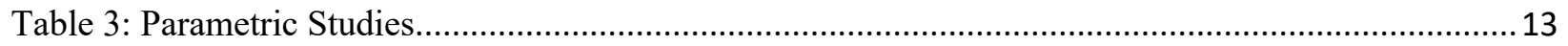

Table 4: Base Model Flow Periods and Productivity Index ................................................................... 15

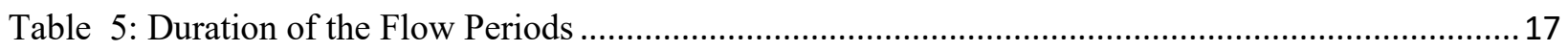

Table 6: Productivity Index for Different Fracture Half-Lengths ....................................................... 17

Table 7: PERCENT Change RELATIVE TO THE BASE MODEL .............................................................. 18

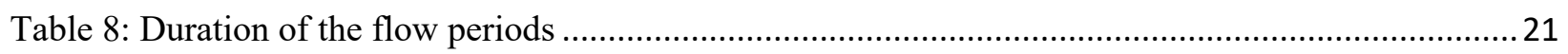

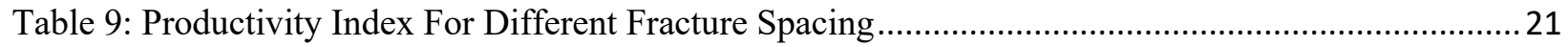

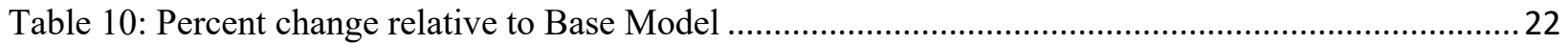

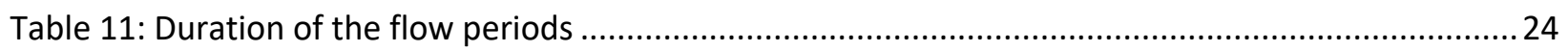

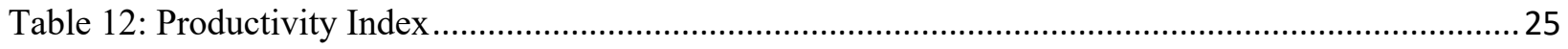

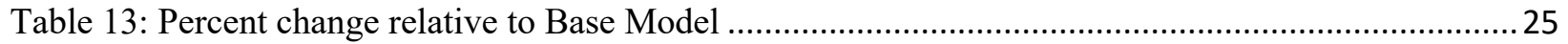




\section{Nomenclature}

$\overline{\mathrm{P}_{\mathrm{a}, \mathrm{R}}} \quad$ Adjusted average reservoir pressure, $\mathrm{psi}$

$\mathrm{P}_{\mathrm{a}, \mathrm{wf}} \quad$ Adjusted wellbore flowing pressure, psi

$\mathrm{P}_{\mathrm{e}} \quad$ External boundary radius pressure. Field units psi.

$c_{\mathrm{t}} \quad$ Formation compressibility, $\mathrm{psi}^{-1}$

$\mathrm{q}_{\mathrm{sc}} \quad$ Production rate at standard condition, Mscf/D

$\emptyset \quad$ Reservoir porosity

$\Delta \quad$ Difference operator

A Drainage area, $\mathrm{ft}^{2}$

h Reservoir thickness

$\mathrm{T} \quad$ Reservoir temperature, ${ }^{\circ} \mathrm{F}$

Z Gas-compressibility factor

G Initial gas in place, Mscf

J Gas productivity index, $\frac{\left(\frac{\text { MMcf }}{\text { day }}\right)}{\text { psi }}$

$\mathrm{Pa} \quad$ Adjusted reservoir pressure, psi

$\mathrm{m}(\mathrm{p}) \quad$ Gas pseudopressure, psi

q Total surface flow rate at standard conditions, $\frac{\text { MMcf }}{\text { day }}$

$\mu \quad$ Gas viscosity, $\mathrm{cp}$

$t_{a} \quad$ Adjusted time, hours

$P_{a} \quad$ Adjusted pressure, psi 
$\begin{array}{ll}t_{a p} & \text { Pseudo time, } \frac{h r}{c p} p s i^{-1} \\ P_{p} & \text { Pseudo pressure, } \frac{p s i^{2}}{c p}\end{array}$ 


\section{CHAPTER 1: INTRODUCTION}

Productivity Index, defined as the ratio of the flow rate to pressure-drawdown, is commonly used to analyze the performance of the well and predict the production rates under different conditions. It is challenging to determine the productivity index for a well completed in an unconventional reservoir because the of the unsteady-state flow conditions.

The unconventional gas formations such Marcellus Shale are characterized by ultra-low permeability. One way to improve gas productivity is to drill a horizontal well. Horizontal wells allow for more contact with the formation and consequently increase the total gas production from low permeability formations.. However, it is challenging to drain the ultra-low permeability reservoirs in a reasonable time frame with horizonatal wells. An effective way to increase the productivity of horizontal well completed in ultra-low permeability reservoir is multi-stage hydraulic fracturing. During hydraulic fracturing water, sand, and other ingredients are injected under high-pressure to forms fractures in the rock. These hydraulic fractures provide high permeability pathways for the gas to flow to the well. If these high permeability flow paths intercept the natural fractures in the formation, commercial natural gas production can be achieved form the shale (Navarro 2011).

This research aims to evaluate the impact of hydraulic fracture properties on the transient productivity index for a horizontal well with multiple hydraulic transverse fractures drilled in an ultra-low permeability gas formation. Additionally, the impacts of different hydraulic fractures configurations are investigated. 


\section{CHAPTER 2: LITERATURE REVIEW}

\subsection{Productivity Index}

The productivity index is one of the common measurements used to evaluate a well's ability to produce hydrocarbons. It is the volume of fluid delivered per psi of drawdown at the sandface. Productivity index is the ratio of the production rate (q) at the surface to the pressure drawdown (pressure drop) at the midpoint of the producing interval, $\left(P_{r}-P_{w f}\right)$, where $P_{w f}$ is the flowing pressure at the wellbore, and $P_{e}$ is the pressure at the external boundary (formation pressure).

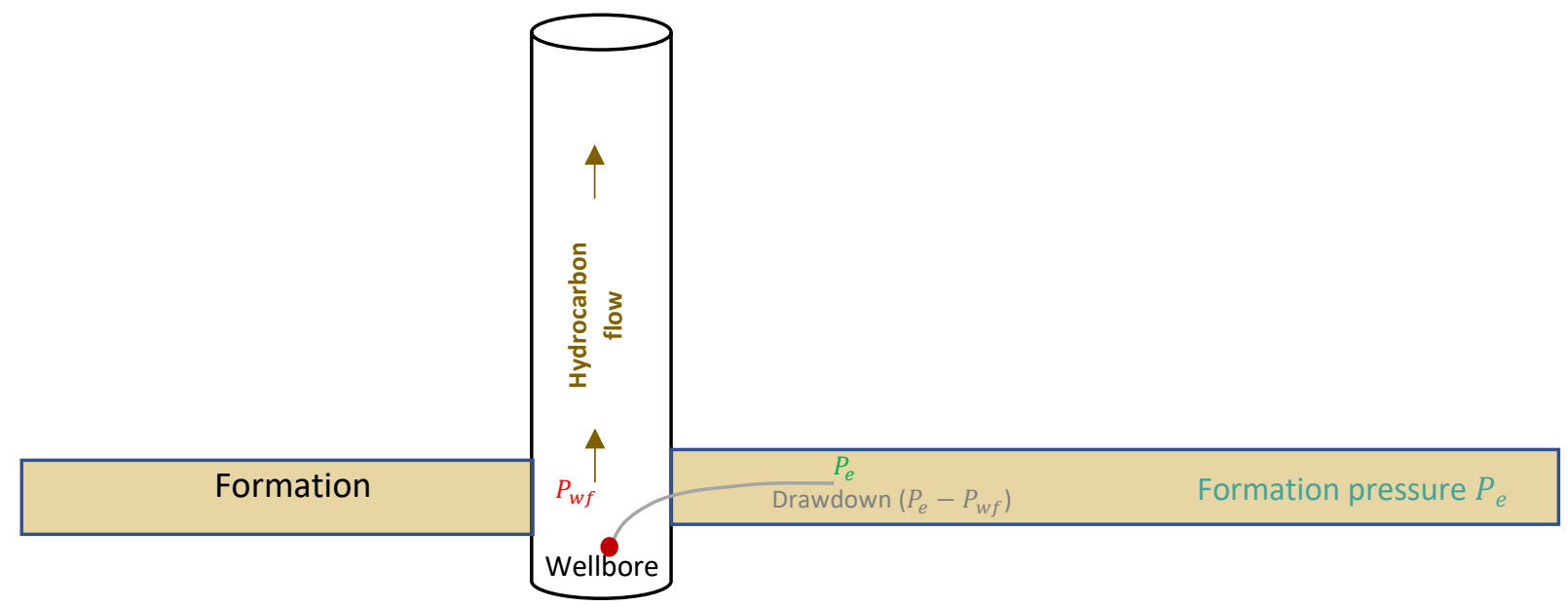

Figure 1: Productivity Index

During the steady-state condition, the outer boundary pressureremains constant $P_{e}=P_{a, R}$ and therefore, the productivity index remains constant.

$$
J=\frac{q}{\left(P_{a, R}-P_{a, w f}\right)}
$$


During pseudo-steady-state, the outer boundary pressure, $P_{e}$, decreases at the same rate as the average reservoir pressure. $\overline{P_{a, R}}$. The bottom-hole flowing pressure, $P_{a, w f}$, also decrease at the same rate as the average reservoir pressure; thus, the term in the denominator of the productivity index remains constant. As a result, The productivity index remains constant.

$$
J=\frac{q}{\left(\overline{P_{a, R}}-P_{a, w f}\right)}
$$

During the unsteady-state, the productivity index is not constant.

Transient productivity index is a convenient means of discussing the productivities of Horizontal wells in tight formations (Medeiros, Ozkan, and Kazemi 2008). The cumulative productivity index can is a measure of cumulative production per average drawdown.

$$
J=\frac{q}{\left(\overline{P_{a, R}}-P_{a, w f}\right)}
$$

The transient productivity index could also be evaluated using the reservoir properties as as a function of gas pseudo-pressure, $m(p)$ (Medeiros, Ozkan, and Kazemi 2008). This definition is applicable to both transient and boundary-dominated flow. The average reservoir pressure can be obtained from an estimated gas in place:

$$
J=\frac{q_{s c}(t)}{\Delta m(p)-\Delta m(\bar{p})}=\frac{q_{s c}(t)}{\Delta m(p)-\frac{2.356 T q_{s c t a}}{\Phi\left(\mu c_{t}\right)_{i} A h}}
$$

Where: 


$$
\begin{gathered}
\Delta m(\bar{p})=m\left(p_{i}\right)-m(\bar{p}) \\
t a=\frac{\left(\mu c_{t}\right)_{i}}{q_{s c}(t)} \frac{Z_{i} G}{2 p_{i}}\left[m(\bar{p})-m\left(p_{w f}\right)\right] \\
t_{a}=\text { material balance time }
\end{gathered}
$$

\subsection{Pseudo-pressure}

Pseudo-pressure, $P_{p}$, accounts for the changes in gas compressibility and viscosity as a function of pressure. Adjusted pressure is used to convert the units of pseudo pressure $\frac{p s i^{2}}{c p}$ to psi.

Pseudo time, $t_{a p}$, accounts for the changes in gas compressibility, gas viscosity, and formation porosity as a function of pressure and time. Adjused time is used to convert the units of pseudo time $\frac{h r}{c p} p s i^{-1}$ to hours.

The spreadsheet takes the reservoir temperature and gas gravity as inputs. For every pressure step, starting from $p^{\prime}=1 p s i$ till the specified reservoir pressure $p^{\prime}=p$, it calculates the term $\frac{2 p^{\prime}}{\mu z}$. The summation of the area under the curve of $\frac{2 p^{\prime}}{\mu z}$ vs. $p$ is the pseudo pressure, $P_{p}$. The same concept can be used to calculate the adjusted time.

\subsection{Flow Regimes}

The productivity index depends on the flow period of the producing well. When the well starts to produce, hydrocarbons flow into the wellbore, the pressure at the wellbore, $P_{w f}$, drops instantaneously, causing a pressure disturbance to form and move away from the wellbore, 
towards the reservoir boundaries. If the reservoir boundary does not allow fluid to flow, it is called "No Flow Boundary". The pressure disturbance results from movement of hydrocarbon molecules from areas of high pressure to areas of low pressure. The speed at which the pressure disturbance travels depends on the properties of the reservoir rock (permeability, porosity, and compressibility) and the the reservoir fluid properties (viscosity and compressibility). Diffusivity, which the combination of the rack and fluid properties, is used ro define the pressure disturbance propagation behavior.

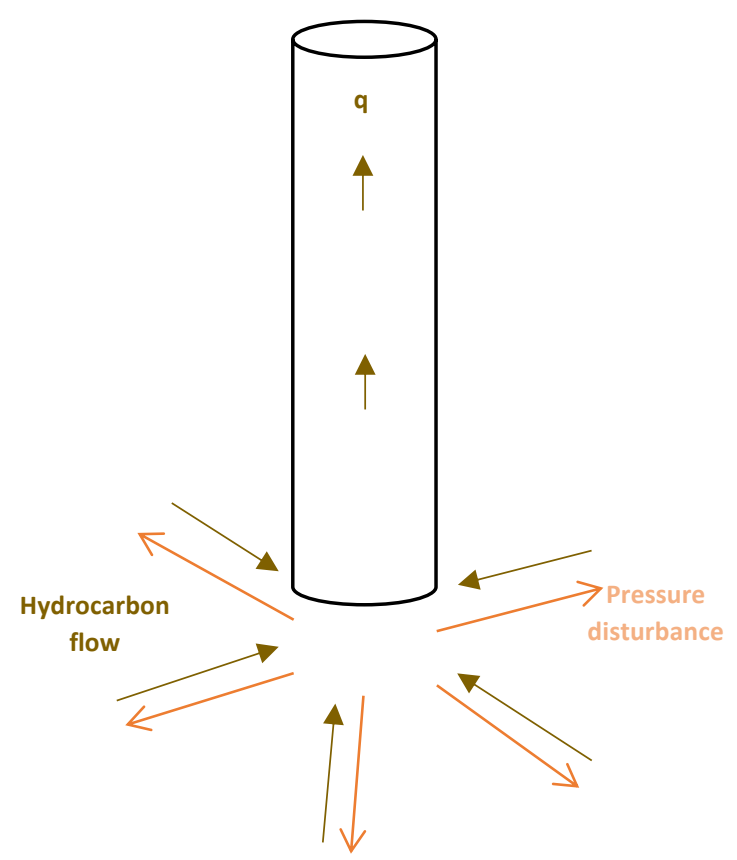

Figure 2: Pressure Disturbance 


\subsection{Reservoir Boundaries}

In the analytical solution to the diffusivity equation, the external boundary condition is selected to be either infinite-acting (case a) or boundary dominated (cases b,c).

a) The pressure at the outer boundary at $(r=\infty)$ of the reservoir remains at the initial reservoir pressure $\left(P_{i}\right)$. Referred to as Infinite-acting condition.

b) There is no-flow at the outer boundary and the pressure gradient at the boundary $\left(\frac{d P}{d r}\right)$ is zero. Referred to as Pseudo-steady-state condition.

c) Constant Pressure Outer Boundary: The pressure at the boundary remains constant. Referred to as Steady-state condition.

\subsection{Flow Regimes in Unconventional Reservoir}

In the ultra-lowpermeability unconventional gas reservoirs, the infinite-acting period can last for most of the well's lifetime (Stewart, 2011).

The graph of $\log p_{D}$ versus $t_{D} \log t_{D}$ can be used to display the solution to the diffusivity equation. A plot of the actual pressure difference $\Delta p=p_{i}-p_{w f}$ versus real time t on a $\log -\log$ scale will have exactly the same shape as the dimensionless theoretical solution provided the data correspond to the model. The term "derivative" refers to the local slope of the appropriate semilog plot and is given the symbol p'. For a constant drawndown p' = dpwf/d(lnt). A derivative $\log -\log$ diagnostic plot is presentation of $\mathrm{p}^{\prime}$ versus $\mathrm{t}$ on log-log scales. Extraction of the logarithmic derivative $\mathrm{p}^{\prime}$ magnifies the fine detail of the basic semilog graph and enhances interpretation particularly in connection with reservoir heterogeneity. 
The diagnostic plot is divided into three main regions ((“Http://Www.Fekete.Com/San/Webhelp/Welltest/Webhelp/Content/Html_files/Reference_mat erials/Flow_regimes.Htm," n.d.):

- Early time region: Wellbore and near-wellbore

In multi-fractured horizontal wells, the observed flow regimes in this region include wellbore storage, vertical radial flow within the fractures, linear flow within the fractures, and bilinear flow.

- Middle time region: Infinite-acting

In multi-fractured horizontal wells, the observed flow regimes are early linear (toward fractures), early radial flow (around each fracture before interference between fracs), linear flow within the fractures, and bilinear flow.

- Late time region: Boundary dominated

In multi-fractured horizontal wells, pseudo-steady state flow occurs.

Identifying the flow regimes from the log-log derivative plot:

- The wellbore dominated period is detected from the unit-slope line on log-log $\Delta P_{a} v s \Delta t_{a}$ and $\log -\log \Delta P_{a, l n}^{\prime} v s \Delta t_{a}$

- Infinite-acting period is is idenfitied by having a slope, $\mathrm{m}$ ', equal to zero on the log-log $\Delta P_{a, l n}^{\prime}$ vs $\Delta t_{a}$

- Boundary dominated period occurs after the infinite-acting period and is detected by any deviation from $m^{\prime}=0$. 
Figure 3 illustrates the typical pseudo-pressure derivative responses for a horizontal well in a homogenous, tight formation and Figure 4 illustrates the typical pressure derivative responses for a horizontal well with two hydraulic fractures.

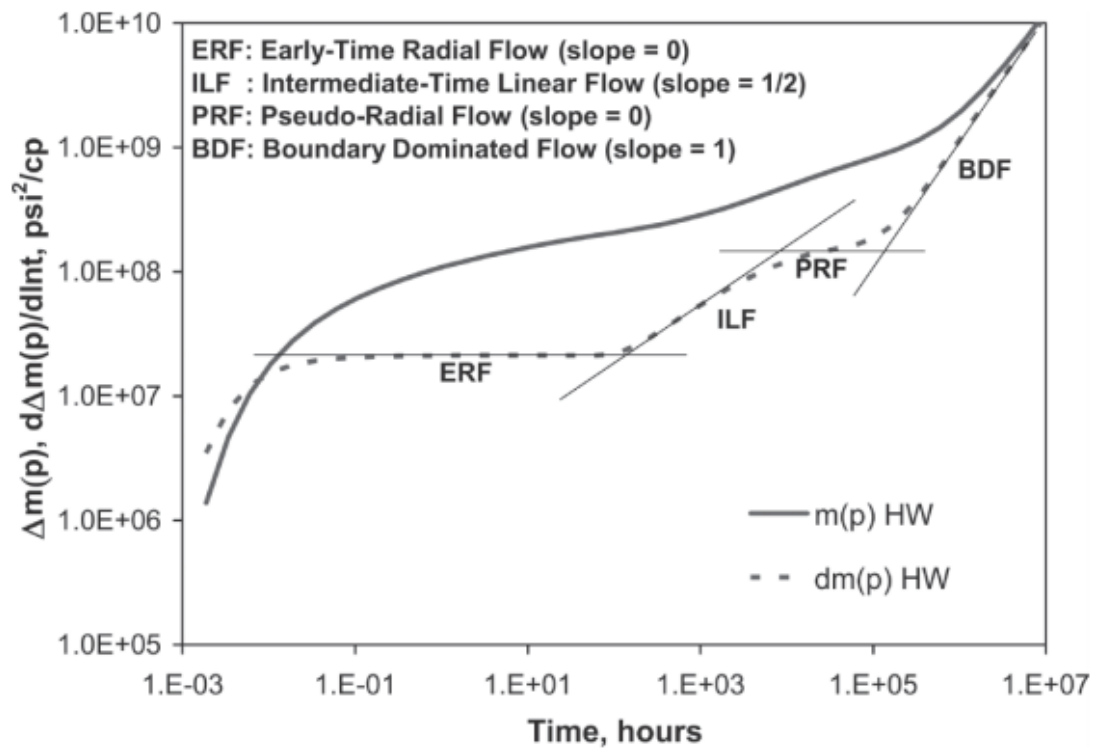

Figure 3: Psuedo-Pressure Derivative Responses for a Horizontal well in a Homogenous Reservoir (After Medeiros et al.2008)

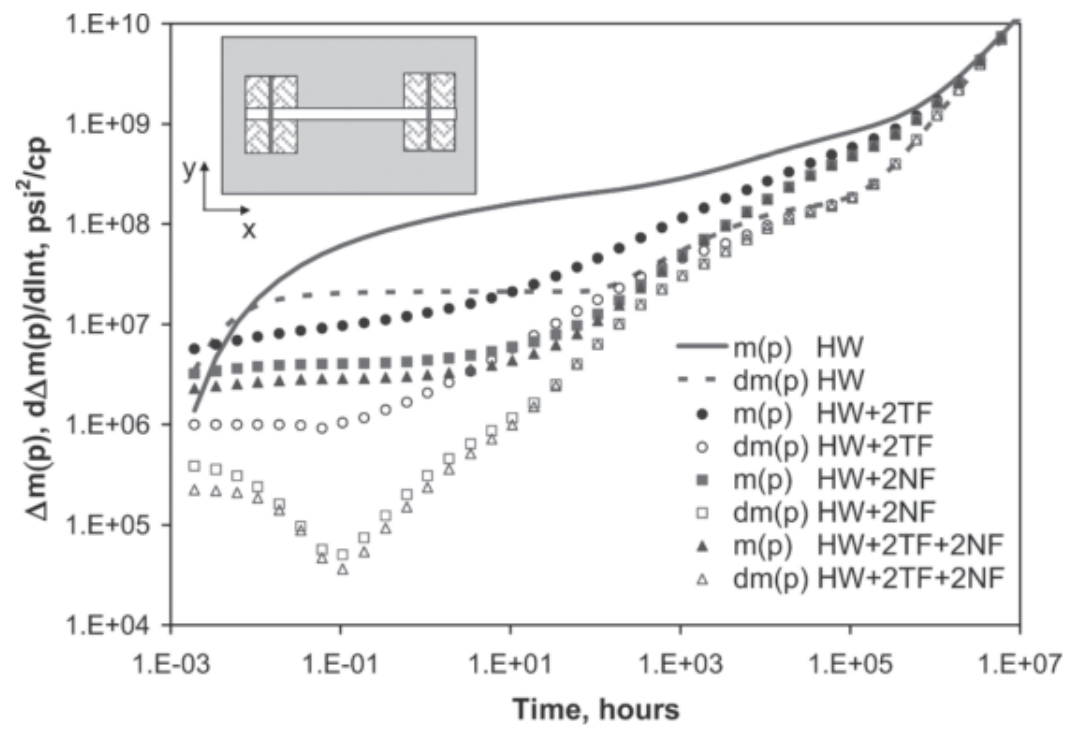




\section{Figure 4. Psuedo-Pressure Derivative Responses for a Horizontal well with Two Transverese Hydraulic Fractures (After Medeiros et al.2008)}

\subsection{Unconventional Shale Reservoir}

Shale rock contains significant amounts of natural gas. Natural gas primarily consists of methane $\left(\mathrm{CH}_{4}\right)$, burns cleanly and emits the lowest quantity of carbon dioxide per calorie of any fossil fuel. Shale gas production is one of the most rapidly expanding trends in onshore domestic oil and gas exploration and production. The percent contribution of natural gas to the U.S. energy supply is expected to remain constant for the following years to come. Some of the natural gas uses include industrial, commercial, electrical generation sectors, and residential heating. (Nash, 2010). Each of the shale basins is different, and each has a unique set of exploration criteria and operational challenges.

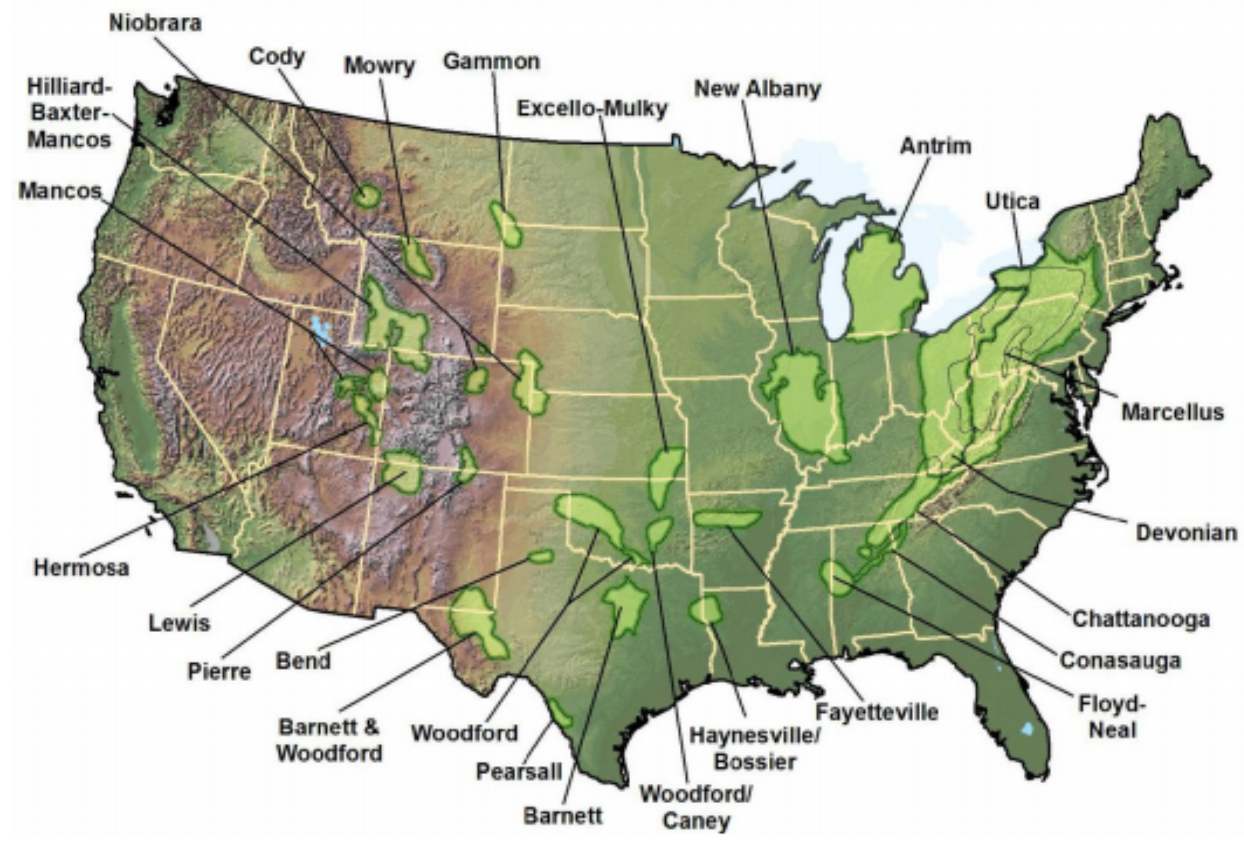

Figure 4: United States Shale Basins

(Nash, 2010) 
Unconventional reservoirs have changed the united states' industry; it allowed gas export. Unconventional reservoirs are far from being well understood due to their complexities in the flow system and heterogeneity. Unlike conventional reservoirs, the gas in shale reservoirs does not flow naturally to the surface due to the low permeability of the formation. The shale reservoir needs to be hydraulically fractured, creating pathways and increasing the permeability, allowing the gas to produce. Shale reservoirs are heterogeneous where the vertical and horizontal permeabilities are not the same.

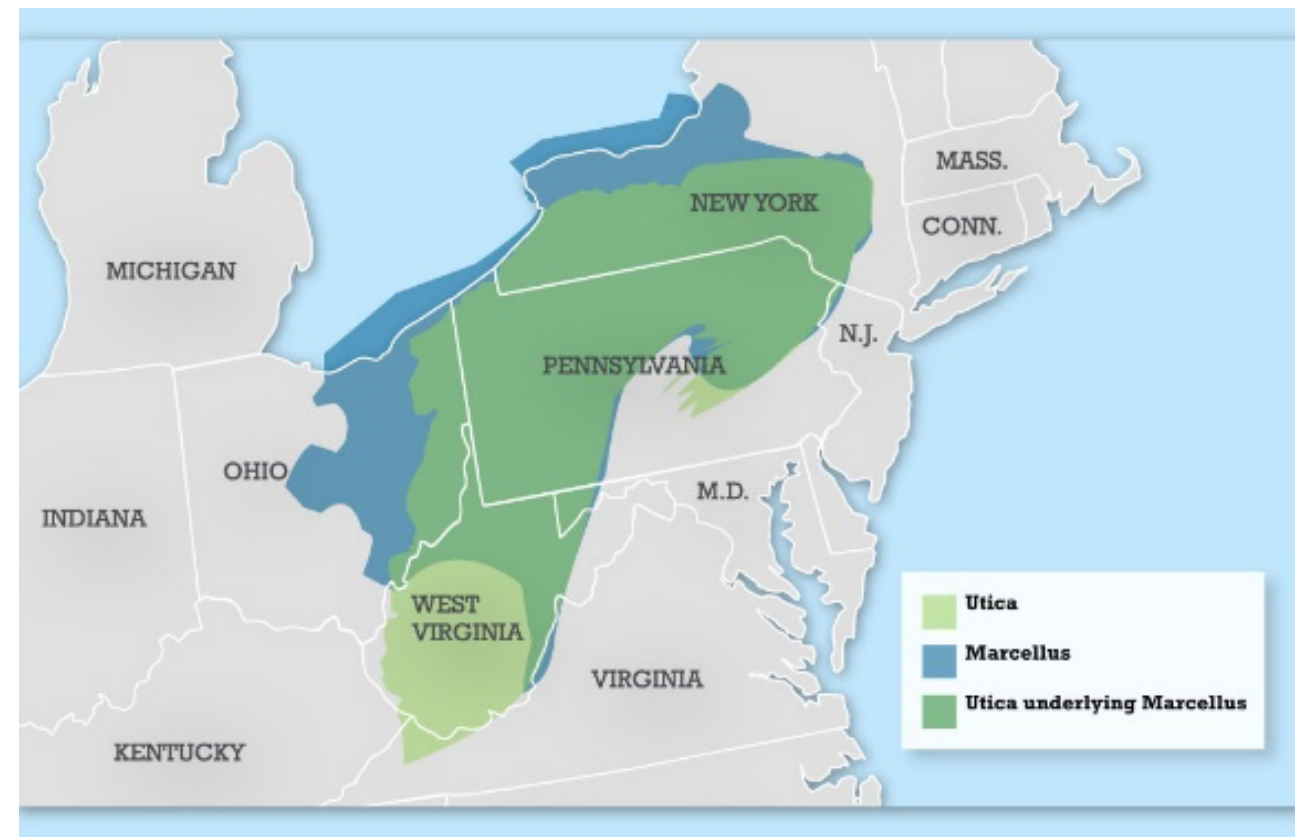

Figure 5 : Marcellus and Utica Shale Formation Map

(“Https://Marcelluscoalition.Org/Pa-Map/,” n.d.)

\subsection{CMG Software}

The CMG software package is used to build a reservoir model for an oil or a gas reservoir. The CMG model simulate the behavior of the reservoir based on the input that is provided such as reservoir rock properties, fluid types, initial reservoir parameters, hydraulic fractures properties, and Adsorption characteristics (Langmuir constants) for unconventional reservoir . A reservoir 
model was developed using CMG-GEM to simulate the base case for the horizontal well with hydraulic fractures in this study. A logarithmically-spaced, locally refined, dual-porosity (LS-LRDK) reservoir model was adopted to effectively simulate hydraulic fracture and natural fracture behavior. The dual permeability model was selected to incorporate the naturally fractured nature of shales, and the logarithmic refinement was required to capture the transient effects around the hydraulic fracture. Logarithmically-spaced gridding would allow for the fine gridding required around the fracture, but it would not create unnecessary grid refinement far away from the fracture. The dual-permeability model accounts for the flow that can occur in the natural fractures, in the matrix, and in transition from the matrix to natural fracture.

\section{CHAPTER 3: METHODOLOGY}

The objective of the study is to evaluate the transient productivity index for a horizontal well with multiple hydraulic transverse fractures drilled in an ultra-low permeability gas formation. Additionally, the impacts of different hydraulic fractures configurations are investigated. The general methodology that eas employed to achive this objective is as follow:

1) The numerical reservoir simulator (CMG-GEM, 2019) was utilized to build the base case model, and obtain the production times, reservoir pressures, and gas flow rates. Table 1 summarizes the reservoir properties, and Table 2 shows the fracture properties for the base model (El Sgher, Aminian, and Ameri 2018).

2) The reservoir pressures, obtained from the model, were converted to adjusted pressures, and the production times were converted to adjusted times:

$$
P_{a}=\left(\frac{\overline{\mu z}}{2 \bar{p}}\right) * \text { Pseudopressure }
$$




$$
t_{a}=\left(\overline{\mu c_{g}}\right) * t_{a p}
$$

Where,

$$
\begin{gathered}
\text { Pseudopressure }=\int_{0}^{p} \frac{2 p^{\prime}}{\mu z} d p^{\prime} \\
t_{a p}=\int_{0}^{t} \frac{d t^{\prime}}{\mu c_{g}} d p^{\prime}
\end{gathered}
$$

3) The flow regimes were identified from the log-log derivative plot.

4) The productivity index was calculated for the infinite-acting period.

$$
J=\frac{q}{\left(\overline{P_{a, R}}-P_{a, w f}\right)}
$$

5)Parametric Studies

The parametric studies, using the base model, were conducted to investigate the impact of fracture

\begin{tabular}{|c|c|c|}
\hline Reservoir Parameters & Values & Units \\
\hline Model Dimensions $(\mathbf{L} \times \mathbf{W} \times \mathbf{H})$ & $4000 \times 1000 \times 90$ & ft. \\
\hline Initial Reservoir Pressure & 4700 & psia \\
\hline Fissure Porosity & 0.0001 & Fraction \\
\hline Matrix Porosity & 0.045 & Fraction \\
\hline Fissure Permeability i, j, k & $0.001,0.001,0.0001$ & md \\
\hline Matrix Permeability i, j, k & $0.0004,0.0004,0.00004$ & md \\
\hline Water Saturation & 0.15 & Fraction \\
\hline Rock Density & 120 & $\mathrm{lb} / \mathbf{f t}^{3}$ \\
\hline Wellbore Pressure & 500 & Psia \\
\hline Langmuir Pressure & 240 & psi \\
\hline Langmuir Volume & 0.032 & gmol/lb \\
\hline
\end{tabular}
half-length, fracture conductivity, and fracture spacing on the duration of transient flow and the productivity index. Table 3 shows parameters and their values used for parametric studies.

Table 1: Reservoir Properties 
Table 2 : Hydraulic Fracture Properties

\begin{tabular}{|l|c|c|}
\hline \multicolumn{1}{|c|}{ Parameter } & Value & Unit \\
\hline Fracture Half-length & $\mathbf{1 2 0}$ & ft. \\
\hline Fracture Conductivity & $\mathbf{2 5}$ & md-ft \\
\hline Number of Hydraulic Fractures & $\mathbf{8}$ & dimensionless \\
\hline Stage Spacing & $\mathbf{3 0 0}$ & ft. \\
\hline
\end{tabular}

Table 3: Parametric Studies

\begin{tabular}{|c|c|c|c|}
\hline Parameters & Base Case & Range & \\
\hline Fracture Half-length, $X_{f}$ & 120 & $50-400$ & ft. \\
\hline $\begin{array}{l}\text { Fracture Conductivity } \\
\mathbf{K}_{\mathrm{f}}^{*} \mathbf{W}_{\mathbf{f}}\end{array}$ & 25 & $5-25$ & md-ft. \\
\hline $\begin{array}{l}\text { Fracture Stage Spacing } \\
\text { with Increasing and } \\
\text { Decreasing the number of } \\
\text { stages }\end{array}$ & $\begin{array}{c}300 \\
\text { (8 stages) }\end{array}$ & $\begin{array}{c}80 \text { (30 Stages), } 200 \\
\text { (14 Stages), and } \\
400 \text { (6 Stages) }\end{array}$ & ft. \\
\hline
\end{tabular}




\section{CHAPTER 4: RESULTS AND DISCUSSION}

\subsection{Base Model Results}

Figure 7 is a plot of the adjusted pressure derivative responses for the base model. The plot was used to identify the flow periods. The boundary-dominated period starts when the derivative curve, in orange, deviates from the infinite-acting period (slope $=0$ ). Table 4 presents the results obtained from Figure 7. Figure 8 shows the the average productivity index forthe base model.

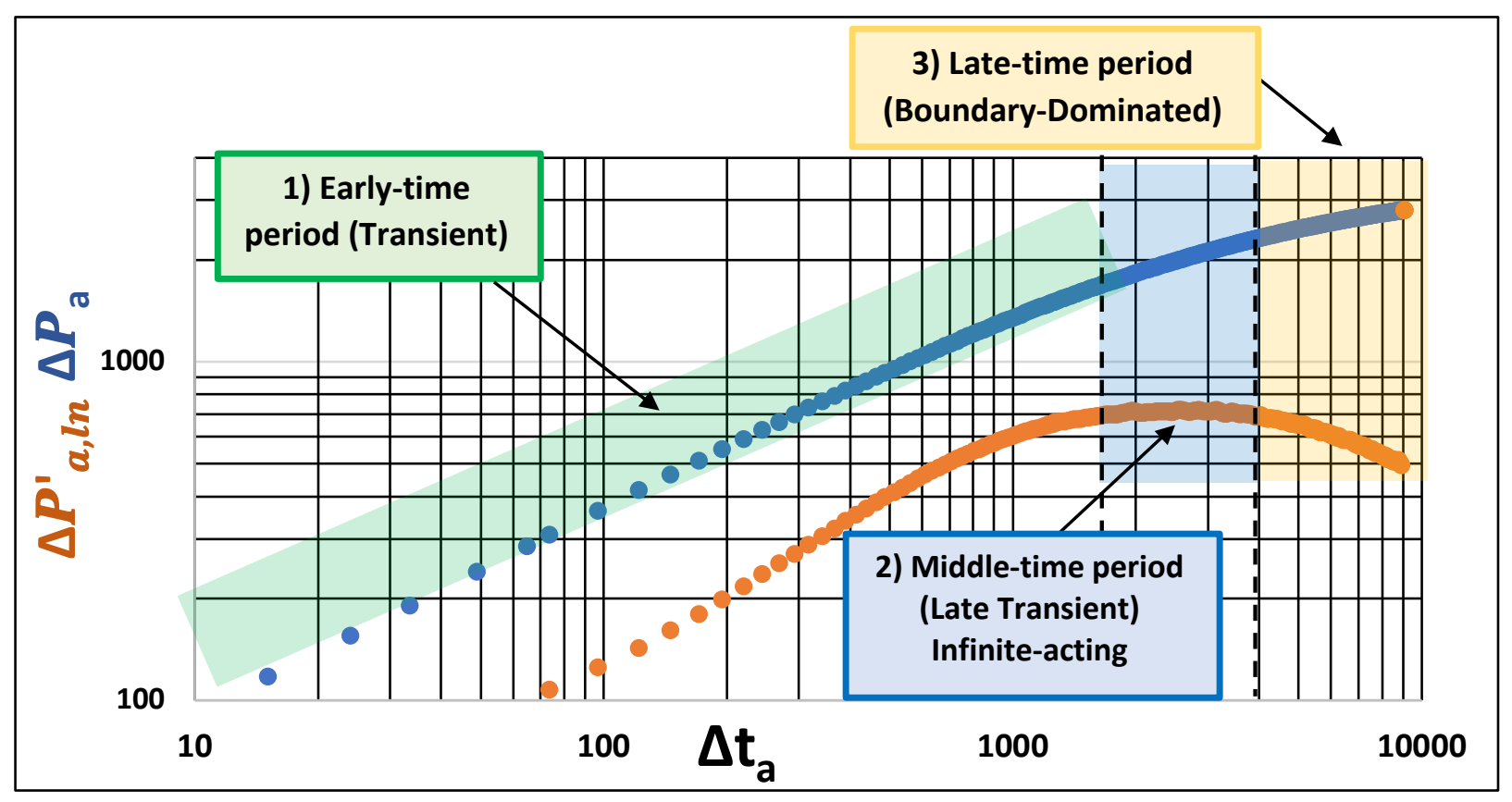

Figure 6: Adjusted Pressure Derivative Responses 


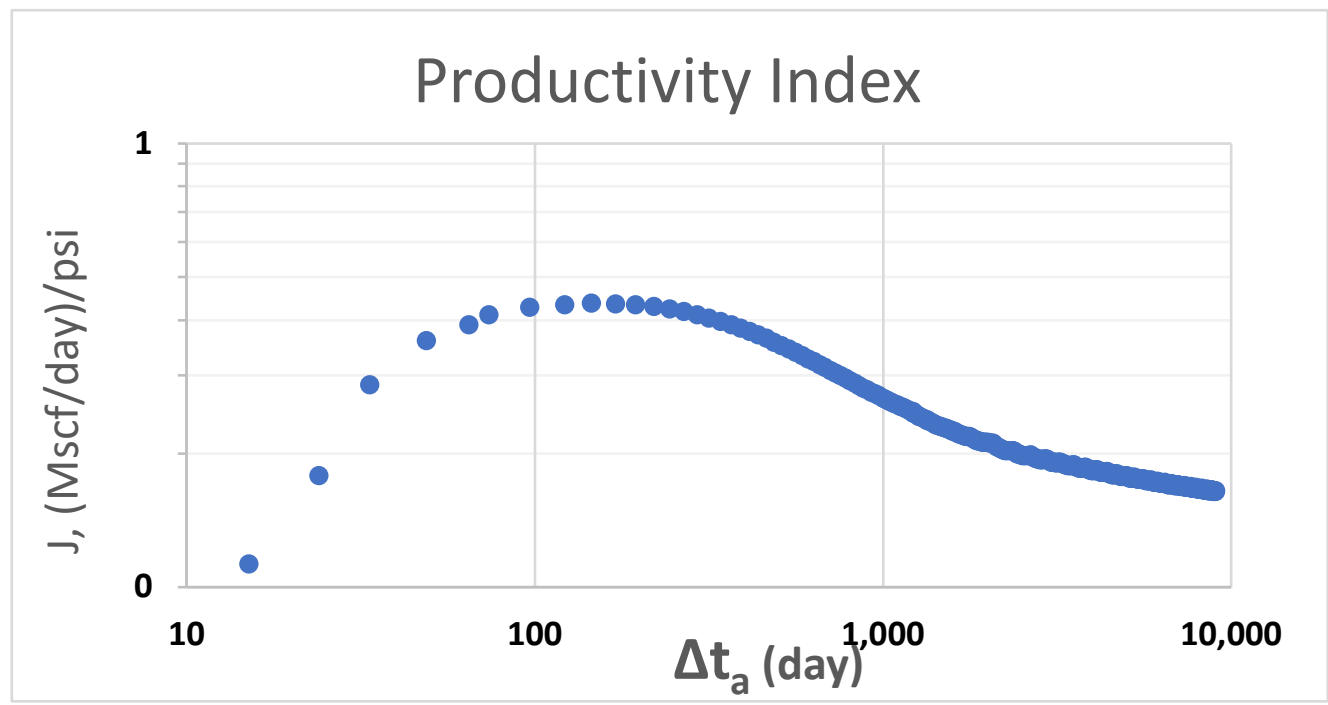

Figure 7: Productivity Index

Table 4: Base Model Flow Periods and Productivity Index

\begin{tabular}{|c|c|c|c|}
\hline Flow Period & $\begin{array}{c}\text { Range } \\
\text { (days) }\end{array}$ & $\begin{array}{c}\text { Duration } \\
\text { (years) }\end{array}$ & $\begin{array}{c}\text { Average } \\
\text { Productivity Index } \\
\text { (Mscf/day)/(psi) }\end{array}$ \\
\hline $\begin{array}{c}\text { Early-time period } \\
\text { (Transient) }\end{array}$ & $0-1,840$ & 5.04 & 0.249 \\
\hline $\begin{array}{c}\text { Middle-time period } \\
\text { (Late Transient) }\end{array}$ & $1,840-3,800$ & 5.37 & 0.201 \\
\hline $\begin{array}{c}\text { Late-time period } \\
\text { (Boundary-Dominated) }\end{array}$ & $3,800-9,000$ & 14.25 & 0.177 \\
\hline
\end{tabular}




\subsection{Parametric Study Results}

\subsubsection{Imapct of Fracture half-length}

Figure 9 is a plot of the adjusted pressure derivative responses for for different fracture halflengths. The flow period durations are given in Table 5. As the fracture half-length increases, the early-time period ends earlier, the middle-time period starts and ends earlier, and the latetime period starts earlier. Figure 10 shows the the average productivity index for different fracture half-lengths. The Productivity Index values for different flow periods are pesented in Table 6. Table 6 shows that as the fracture half-length increases, the productivity index is improved significantly in the early-time period, middle-time period, and the late-time period.

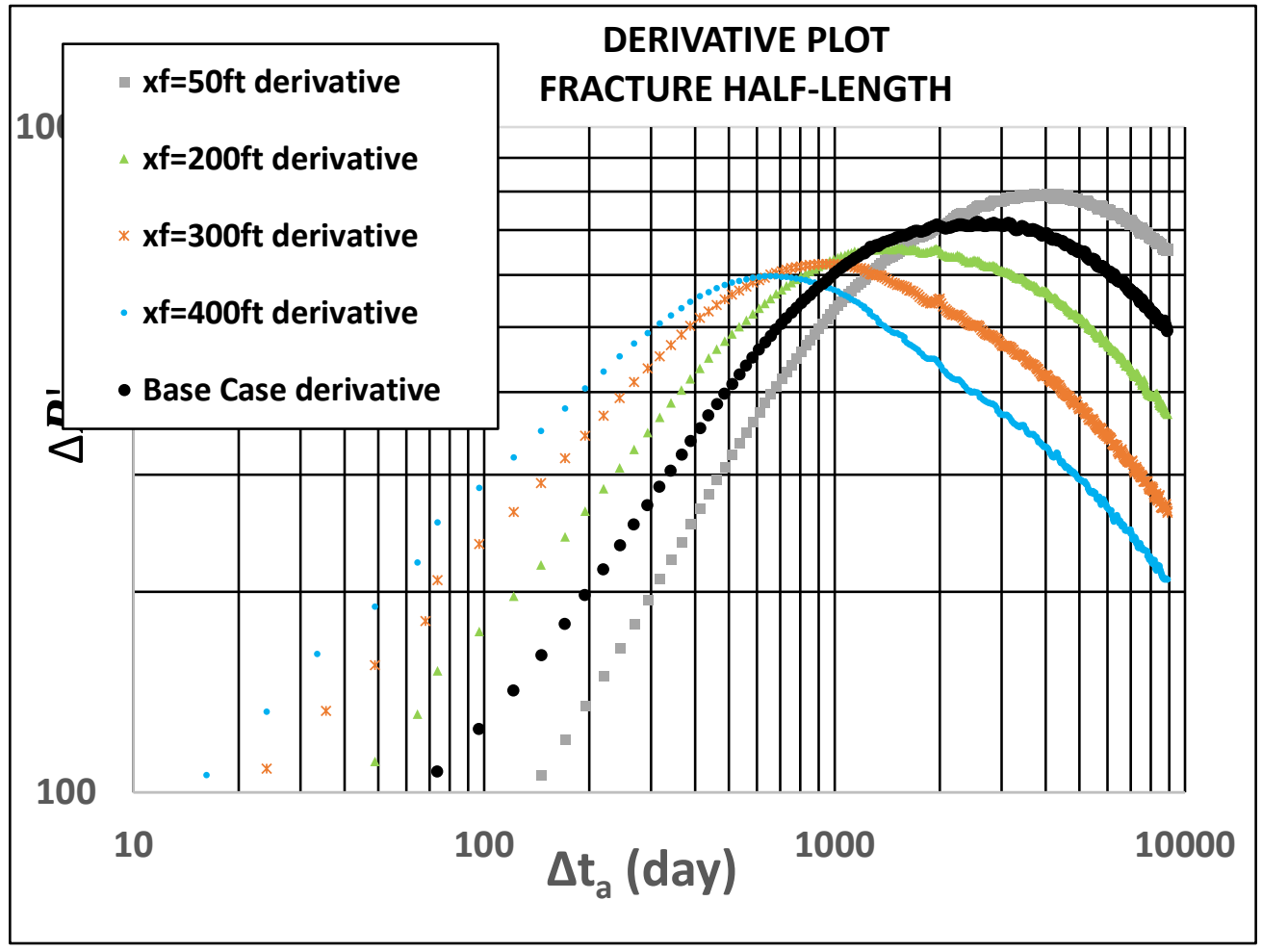

Figure 8: Derivative Responses for different fracture half-lengths 


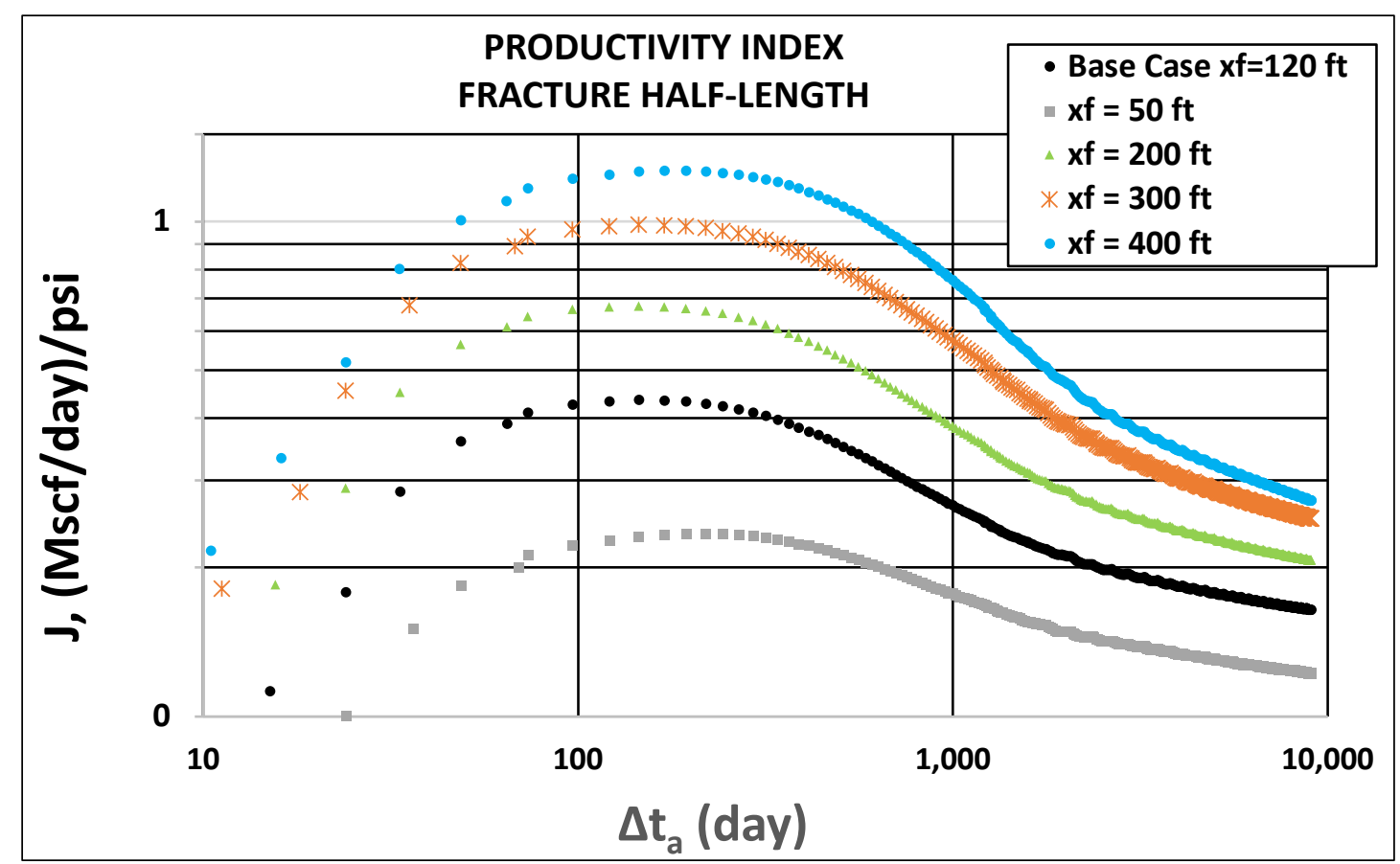

Figure 9: Productivity Index Plot for Different Fracture half-Length

Table 5: Duration of the Flow Periods

\begin{tabular}{|l|c|c|c|c|c|}
\hline Xf, ft. & $\mathbf{5 0}$ & $\mathbf{1 2 0}$ & $\mathbf{2 0 0}$ & $\mathbf{3 0 0}$ & $\mathbf{4 0 0}$ \\
\hline EARLY PERIOD, YEARS & 7.12 & $\mathbf{5 . 0 4}$ & 3.15 & 1.78 & 1.26 \\
\hline MIDDLE PERIOD, YEARS & 8.36 & $\mathbf{5 . 3 7}$ & 2.33 & 1.51 & 1.48 \\
\hline LATE PERIOD, YEARS & 9.18 & $\mathbf{1 4 . 2 5}$ & 19.18 & 21.37 & 21.92 \\
\hline
\end{tabular}

*Base Case

Table 6: Productivity Index for Different Fracture Half-Lengths

\begin{tabular}{|c|c|c|c|}
\hline Flow Periods & Early Period & Middle Period & Late Period \\
\hline $\mathbf{X f}=\mathbf{5 0}$ ft. & 0.152 & 0.136 & 0.127 \\
\hline $\mathbf{X f}=\mathbf{1 2 0}$ ft. $^{*}$ & $\mathbf{0 . 2 4 9}$ & $\mathbf{0 . 2 0 1}$ & $\mathbf{0 . 1 7 7}$ \\
\hline $\mathbf{X f}=\mathbf{2 0 0}$ ft. & 0.391 & 0.318 & 0.236 \\
\hline $\mathbf{X f}=\mathbf{3 0 0}$ ft. & 0.586 & 0.564 & 0.318 \\
\hline $\mathbf{X f}=\mathbf{4 0 0}$ ft. & 0.761 & 0.836 & 0.376 \\
\hline
\end{tabular}

*Base Case

Table 7 shows the percent change, relative to the base model, in the Productivity Index values and the production duration for different flow periods. From Table 7, as the fracture half-length increases, there is a significant percent increase in the productivity index during the early-time period, middle-time period, and the late-time period. The opposite effect is observed when the fracture half-length is shortened, e.g. $x f=50 \mathrm{ft}$. Additionally, 
the fracture half-length significantly impact the production duration in each of the flow periods.

Table 7: Percent Change Relative to the Base Model

\begin{tabular}{|c|c|c|c|}
\cline { 2 - 4 } \multicolumn{1}{c|}{} & Flow Periods & $\begin{array}{c}\text { \% change in } \\
\text { Average J }\end{array}$ & $\begin{array}{c}\text { \% change in } \\
\text { period duration }\end{array}$ \\
\hline \multirow{3}{*}{$\mathbf{X f}=\mathbf{5 0}$ ft. } & Early & $-39 \%$ & $41 \%$ \\
\cline { 2 - 4 } & Middle & $-32 \%$ & $56 \%$ \\
\hline \multirow{3}{*}{$\mathbf{X f}=\mathbf{2 0 0} \mathbf{f t .}$} & Late & $-28 \%$ & $-36 \%$ \\
\cline { 2 - 4 } & Early & $57 \%$ & $-38 \%$ \\
\hline \multirow{3}{*}{$\mathbf{X f}=\mathbf{3 0 0} \mathbf{f t .}$} & Middle & $58 \%$ & $-57 \%$ \\
\cline { 2 - 4 } & Late & $34 \%$ & $35 \%$ \\
\hline & Early & $135 \%$ & $-65 \%$ \\
\hline \multirow{3}{*}{$\mathbf{X f}=\mathbf{4 0 0} \mathbf{f t .}$} & Late & $181 \%$ & $-72 \%$ \\
\cline { 2 - 4 } & Early & $206 \%$ & $50 \%$ \\
\cline { 2 - 4 } & Middle & $317 \%$ & $-75 \%$ \\
\hline & Late & $113 \%$ & $-72 \%$ \\
\hline
\end{tabular}




\subsubsection{Imapct of the Fracture Spacing}

Figure 11 is a plot of the pressure derivative responses. The curves were used to identify the flow periods.

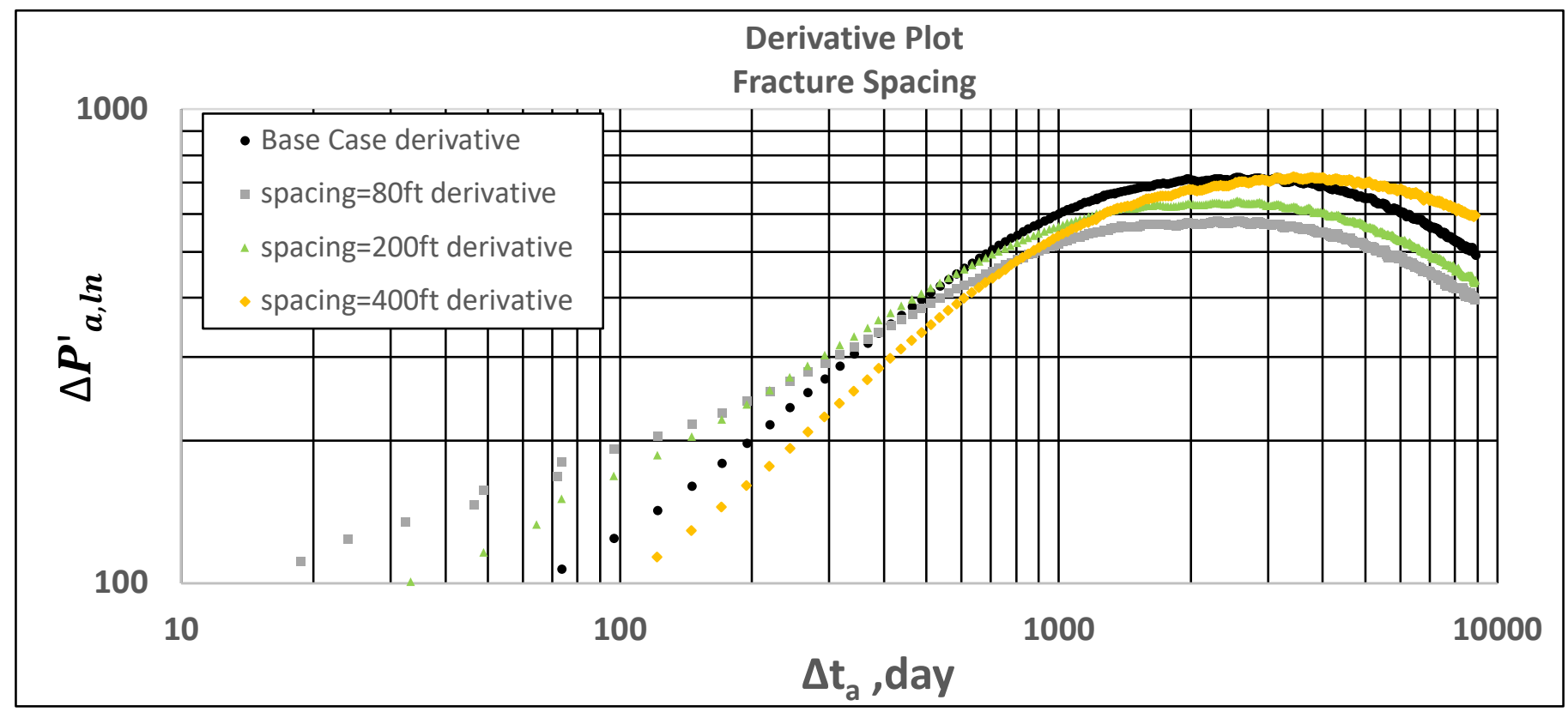

Figure 10: Derivative Responses

Fig. 12 shows the effect of the fracture spacing on the average productivity index. 


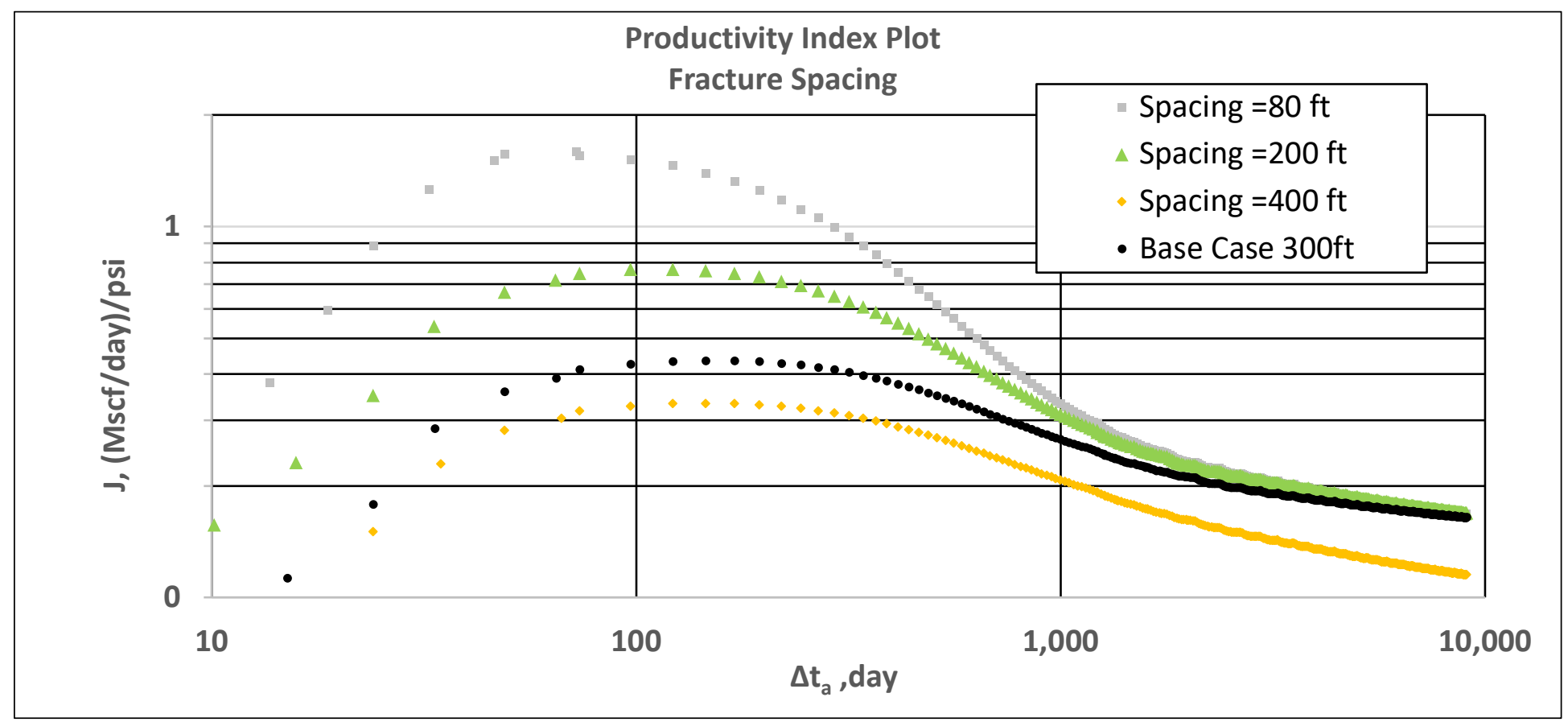

Figure 11: Productivity Index Plot

Table 8 shows the total production time for the selected fracture spacing values in different flow periods. As the fracture spacing is improved, e.g. shorter fracture spacing, the early-time period ends earlier, the middle-time period starts and ends earlier, and the latetime period starts earlier. The opposite effect is observed for when the fracture spacing is longer, e.g. spacing $=400 \mathrm{ft}$. 
Table 8: Duration of the flow periods

\begin{tabular}{|l|c|c|c|c|}
\hline Spacing, ft. & $\mathbf{8 0}$ & $\mathbf{2 0 0}$ & $\mathbf{3 0 0} *$ & $\mathbf{4 0 0}$ \\
\hline EARLY PERIOD, YEARS & 3.84 & 4.38 & $\mathbf{5 . 0 4}$ & 7.67 \\
\hline MIDDLE PERIOD, YEARS & 4.79 & 4.52 & $\mathbf{5 . 3 7}$ & 6.58 \\
\hline LATE PERIOD, YEARS & 16.03 & 15.75 & $\mathbf{1 4 . 2 5}$ & 10.41 \\
\hline
\end{tabular}

*Base Case

Table 9: Productivity Index For Different Fracture Spacing

\begin{tabular}{|c|c|c|c|}
\hline Flow Periods & Early Period & Middle Period & Late Period \\
\hline Spacing $=\mathbf{8 0}$ ft. & 0.5387 & 0.2334 & 0.1872 \\
\hline Spacing $=\mathbf{2 0 0}$ ft.* & 0.3469 & 0.2240 & 0.1863 \\
\hline Spacing $=\mathbf{3 0 0}$ ft. & $\mathbf{0 . 2 4 8 7}$ & $\mathbf{0 . 2 0 0 7}$ & $\mathbf{0 . 1 7 6 5}$ \\
\hline Spacing $=\mathbf{4 0 0}$ ft. & 0.1833 & 0.1403 & 0.1246 \\
\hline
\end{tabular}

*Base Case

The Productivity Index values for different flow periods are pesented in Table 9. As the fracture spacing is improved, e.g.shorter fracture spacing, the productivity index is improved in the early-time period, middle-time period, and the late-time period. The opposite effect is observed for the longer fracture spacing, e.g. $\mathrm{xf}=400 \mathrm{ft}$.

Table 10 shows the percent change, relative to the base model, in the Productivity Index values and the production duration for different flow periods. As the fracture spacing is improved, e.g. shorter fracture half-length, there is a percent increase in the productivity index in the early-time period, middle-time period, and the late-time period. The opposite effect is observed for the longer fracture spacing, e.g. $\mathrm{xf}=400 \mathrm{ft}$. Aditionally, fracture spacing impact the production duration in each of the flow periods. 
Table 10: Percent change relative to Base Model

\begin{tabular}{|c|c|c|c|}
\cline { 2 - 4 } & Flow Periods & $\begin{array}{c}\text { \% Increase in } \\
\text { Average J }\end{array}$ & $\begin{array}{c}\text { \% increase in the } \\
\text { period duration }\end{array}$ \\
\hline \multirow{3}{*}{ spacing = 80ft } & Early & $117 \%$ & $-24 \%$ \\
\cline { 2 - 4 } & Middle & $16 \%$ & $-11 \%$ \\
\hline \multirow{3}{*}{ spacing =200ft } & Late & $6 \%$ & $13 \%$ \\
\cline { 2 - 4 } & Early & $39 \%$ & $-13 \%$ \\
\hline & Middle & $12 \%$ & $-16 \%$ \\
\hline \multirow{3}{*}{ spacing=400ft } & Late & $6 \%$ & $11 \%$ \\
\cline { 2 - 4 } & Early & $-26 \%$ & $52 \%$ \\
\cline { 2 - 4 } & Middle & $-29 \%$ & $22 \%$ \\
\hline
\end{tabular}




\subsection{Fracture conductivity}

Figure 13 is a plot of the pressure derivative responses. The curves were used to identify the flow periods.

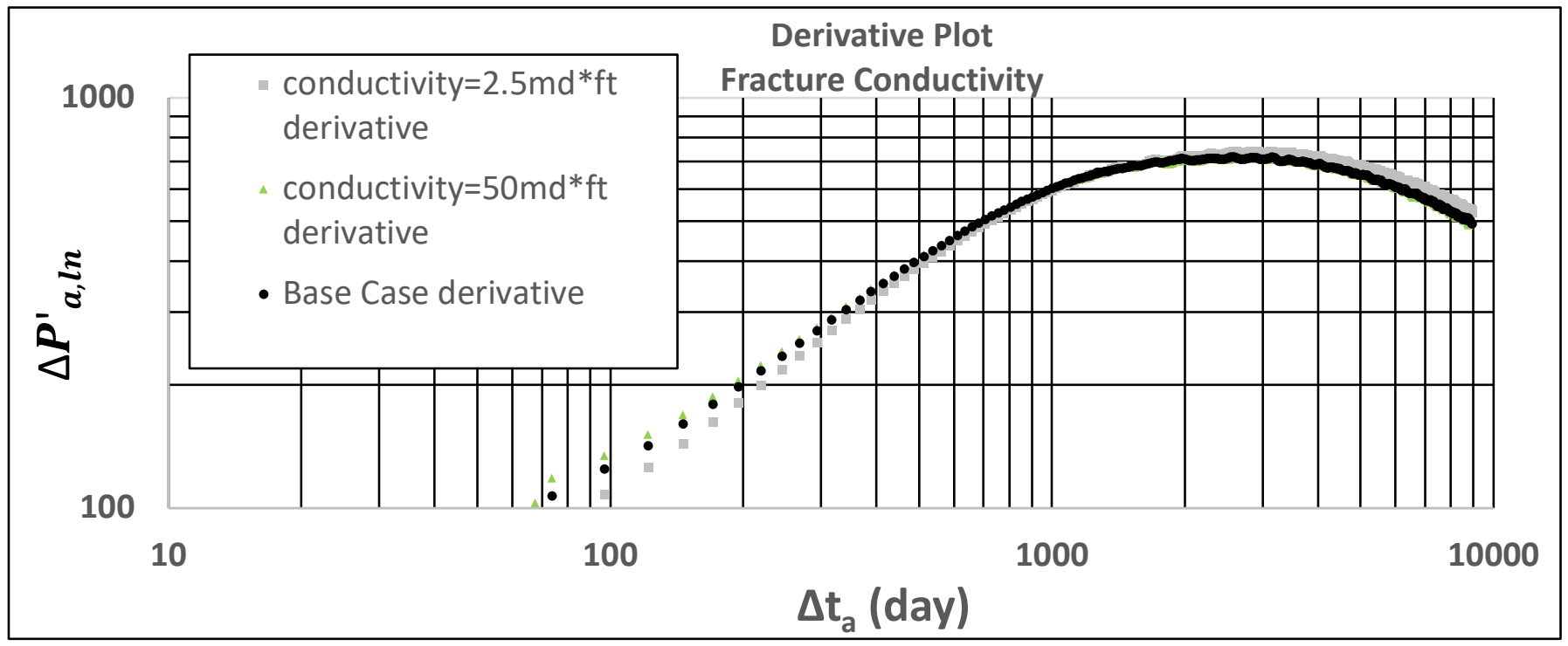

Figure 12: Derivative Responses

Fig. 14 shows the effect of the fracture conductivity on the average productivity index. 


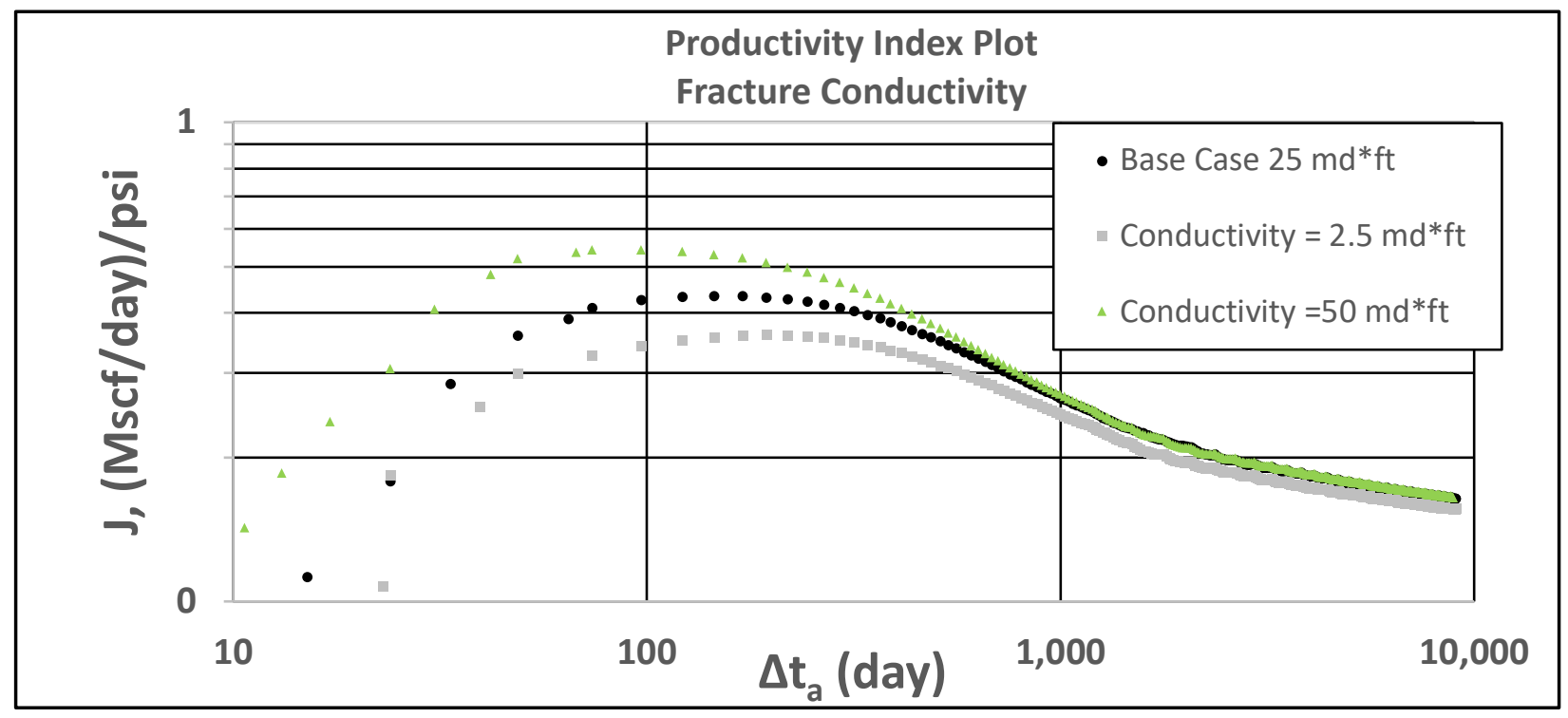

Figure 13: Productivity Index Plot

Table 11 shows the total production time for the selected fracture conductivity values in different flow periods. The fracture conductivity appears to have insignificant impact on the flow periods.

Table 11: Duration of the flow periods

\begin{tabular}{|l|c|c|c|}
\hline Conductivity, md*ft. & $\mathbf{2 . 5}$ & $\mathbf{2 5 *}$ & $\mathbf{5 0}$ \\
\hline EARLY PERIOD, YEARS & 5.34 & $\mathbf{5 . 0 4}$ & 4.66 \\
\hline MIDDLE PERIOD, YEARS & 6.03 & $\mathbf{5 . 3 7}$ & 5.21 \\
\hline LATE PERIOD, YEARS & 13.29 & $\mathbf{1 4 . 2 5}$ & 14.79 \\
\hline
\end{tabular}

*Base Case 
Table 12: Productivity Index

\begin{tabular}{|c|c|c|c|}
\hline Flow Periods & Early Period & Middle Period & Late Period \\
\hline Conductivity $=\mathbf{2 . 5 m d * f t . ~}$ & 0.2320 & 0.1857 & 0.1662 \\
\hline Conductivity $=\mathbf{2 5}$ md*ft.* & $\mathbf{0 . 2 4 8 7}$ & $\mathbf{0 . 2 0 0 7}$ & $\mathbf{0 . 1 7 6 5}$ \\
\hline Conductivity $=\mathbf{5 0}$ m $*$ ft. $^{*}$ & 0.2677 & 0.2041 & 0.1779 \\
\hline
\end{tabular}

*Base Case

The Productivity Index values for different flow periods are pesented in Table 12. The fracture conductivity appears to has insignificant impact on the productivity index.

Table 13 shows the percent change, relative to the base case, in the Productivity Index values and the production duration for different flow periods. The fracture conductivity has little and insignificant impact on both the percent change in the productivity index and the percent change in the production duration in each of the flow periods.

Table 13: Percent change relative to Base Model

\begin{tabular}{|c|c|c|c|}
\hline & Flow Periods & $\begin{array}{c}\% \text { Increase in } \\
\text { Average J }\end{array}$ & $\begin{array}{c}\% \text { increase in the period } \\
\text { duration }\end{array}$ \\
\hline \multirow{3}{*}{ conductivity $=2.5 \mathrm{md}^{*} \mathrm{ft}$} & Early & $-7 \%$ & $6 \%$ \\
\hline & Middle & $-8 \%$ & $12 \%$ \\
\hline & Late & $-6 \%$ & $-7 \%$ \\
\hline \multirow{3}{*}{ conductivity $=50 \mathrm{md} * \mathrm{ft}$} & Early & $8 \%$ & $-8 \%$ \\
\hline & Middle & $2 \%$ & $-3 \%$ \\
\hline & Late & $1 \%$ & $4 \%$ \\
\hline
\end{tabular}




\section{CHAPTER 5: CONCLUSION AND RECOMMENDATION}

Conclusions:

- In an unconventional tigh shale gas reservoir, the majority of the well's lifetime is spent in the early and middle time periods.

- The productivity index for a hydraulically fractured horizontal well completed in the unconventional shale gas reservoir depends on the flow regime and the hydraulic fracture properties.

- The hydraulic fracture half-length, spacing, and conductivity impact both the duration of the flow regimes and the productivity index.

- The Productivity Index is a function of, but not limited to, the fracture-half length, fracture spacing, and fracture conductivity.

- Fracture half-length has significant impact on the production.

- Fracture spacing impacts the production.

- Fracture conductivity does not have a significant impact on the production.

- The fracture half-length affects the productivity index more than fracture spacing and fracture conductivity. Meanwhile, the fracture spacing affects the productivity index more than the fracture conductivity.

Relationship strength with the Productivity Index:

$$
\text { facture half lenght }>\text { fracture Spacing }>\text { fracture conductivity }
$$

- The flow regime periods are a function of, but not limited to, the fracture-half length, fracture spacing, and fracture conductivity. 
- When the fracture half-length is increased, the middle period (infinite-acting period) occurs earlier and lasts for a shorter period. Fracture half-length significantly affect the start, end, and duration of the flow time periods.

- When the fracture spacing is decreased, the middle period (infinite-acting period) occurs earlier and lasts for a shorter period. Fracture spacing does not significantly contribute to the start, end, and duration of the flow time periods.

- When the fracture conductivity is increased, the middle period (infinite-acting period) occurs earlier and lasts for a shorter period. Fracture spacing does not significantly contribute to the start, end, and duration of the flow time periods.

- The fracture half-length affects the flow time regimes and duration more than fracture spacing and fracture conductivity. Meanwhile, the fracture spacing affect is stronger than the fracture conductivity. Relationship strength with the flow regime :

facture half lenght $>$ fracture Spacing $>$ fracture conductivity

Recommendations:

- Perform sensitivity analysis studies to understand the effect of the other parameters to ultimately improve the well's productivity through the Productivity Index.

- Attempt to find a correlation, to predict the Productivity Index, for a gas well with multiple hydraulic fractures. 


\section{References}

gher, Mohamed, Kashy Aminian, and Samuel Ameri. 2018. "Geomechanical Impact on Gas Recovery from Marcellus Shale." In Day 4 Wed, April 25, 2018, D041S009R002. Garden Grove, California, USA: SPE. https://doi.org/10.2118/190054-MS.

“Https://Marcelluscoalition.Org/Pa-Map/." n.d.

“Http://Www.Fekete.Com/San/Webhelp/Welltest/Webhelp/Content/Html_files/Reference_materials/F low_regimes.Htm." n.d.

Medeiros, F, E Ozkan, and H Kazemi. 2008. "Productivity and Drainage Area of Fractured Horizontal Wells in Tight Gas Reservoirs," 10.

Nash, Katelyn M., ed. 2010. Shale Gas Development. Energy Science, Engineering and Technology. New York: Nova Science Publishers.

Navarro, Gabriel L., ed. 2011. Marcellus Shale and Shale Gas: Facts and Considerations. Earth Sciences in the 21st Century. New York: NOVA, Nova Science Publishers, Inc.

Stewart, George. 2011. Well Test Design \& Analysis. Tulsa, Okla: PennWell. 